\title{
НЕКОТОРЫЕ ФЕНОТИПИЧЕСКИЕ ПРИЗНАКИ КАК МАРКЕРЫ ПРЕДРАСПОЛОЖЕННОСТИ К РАКУ ЖЕЛУДКА И ТОЛСТОГО КИШЕЧНИКА
}

\author{
(C) Барсуков В.C. ${ }^{1}$, Дудка В.T. \\ ${ }^{1}$ Кафедра общей патологии и физиологии \\ Орловского государственного университета имени И.С. Тургенева, Орел; \\ ${ }^{2}$ кафедра патологической анатомии Курского государственного медицинского университета, Курск \\ E-mail: barsukovvs@mail.ru
}

Рак желудка и рак толстого кишечника является одним из наиболее распространенных среди злокачественных опухолей человека. На основании изучения клинического и патологоанатомического материала установлено, что наличие у человека славянского этноса голубых глаз, волнистых или курчавых волос на голове и А (II) группы крови является свидетельством повышенной предрасположенности к данным злокачественным опухолям и, по-видимому, к злокачественным новообразованиям вообще. При этом присутствие комплекса описанных фенотипических признаков у пациентов в прогностическом отношении при уже развившейся злокачественной опухоли сопряжено с ее более агрессивным течением. Вместе с тем у опухоленосителей несколько реже встречалась В (III) группа крови, темный цвет глаз, прямой тип волос на голове, что дало основание рассматривать данные признаки как «антираковые».

Ключевые слова: цвет глаз, характер волос, группа крови, предрасположенность к злокачественным опухолям.

\section{SOME PHENOTYPICAL SIGNS AS MARKERS OF PREDISPOSITION TO STOMACH AND COLON CARCINOMA Barsukov V.S. ${ }^{l}$, Dudka V.T. ${ }^{2}$}

${ }^{1}$ General Pathology and Physiology Department of I.S. Turgenev Orel State University, Orel;

${ }^{2}$ Pathological Anatomy Department of Kursk State Medical University, Kursk

Gastric cancer and colon cancer are the most common ones among human malignant tumors. Based on the study of clinical and pathoanatomical material, it is established that the presence of blue eyes, wavy or curly hair on the head and A (II) blood group in a person of the Slavic ethnos is a witness to an increased predisposition to these malignant tumors and, apparently, to malignant neoplasms in general. At the same time, the set of the described phenotypic signs in patients in prognostic relation with already developed malignant tumor is associated with its more aggressive course. At the same time, the III blood group, sombre eyes, straight hair on the head, which gave grounds to consider these signs as "anti-cancer", were somewhat less common in tumor carriers.

Keywords: colour of eyes, type of hair, blood group, predisposition to malignant tumors.

Среди показателей заболеваемости и смертности от новообразований различных органов и систем ведущее место принадлежит злокачественным опухолям органов пищеварительной системы. Так, по некоторым данным, из числа всех, заболевших раком, на органы пищеварения приходится почти 55\% больных, а среди всех умерших от рака - почти у $40 \%$ был рак органов пищеварения. При этом ведущие позиции по данным показателям принадлежат раку толстой кишки и раку желудка $[3,5,6,8]$.

В России при общей смертности от онкологических заболеваний в 300 тысяч человек ежегодно, более 100 тысяч случаев приходится на рак органов пищеварения. При этом одной из проблем, стоящих перед системой здравоохранения нашей страны, является увеличение показателей выживаемости, которые хуже, чем в экономически развитых странах запада. По мнению ведущих онкологов, к важным причинам, обусловливающим данную ситуацию, можно отнести недора- ботки в диагностике злокачественных новообразований $[3,7]$.

Выявление болезни на ранних стадиях и ее профилактика на популяционном уровне решается посредством скрининга на наличие опухоли и предраковых заболеваний в группах риска [4]. Одной из наиболее эффективных мер по снижению летальности от злокачественных опухолей, в развитии которых важное значение имеют генетические факторы, является их обнаружение на доклинической стадии $[6,8]$. Из этого следует принципиальная возможность оценки индивидуальной предрасположенности к злокачественным опухолям путем изучения у конкретного человека некоторых фенотипических признаков, косвенным образом связанных с общим генотипом и таким образом характеризующих его.

Целью исследования явилось изучение значимости ряда фенотипических признаков для определения предрасположенности пациентов к возникновению злокачественных опухолей, а также прогноза течения данных заболеваний. 


\section{МАТЕРИАЛЫ И МЕТОДЫ ИССЛЕДОВАНИЯ}

В ходе работы была проанализирована встречаемость группы крови, цвета глаз (темные: черные, карие, светло-карие; светлые: зеленые, сероголубые, голубые) и характера волос на голове (прямые, вьющиеся или курчавые) у больных раком желудка (РЖ) и раком толстого кишечника (РТК). Указанные признаки относятся к наследуемым, легко учитываются и, главное, имеются уже в детском возрасте, когда риск злокачественной опухоли еще минимален, но уже есть возможность для организации долгосрочных целенаправленных профилактических мероприятий. Данный комплекс фенотипических признаков был нами ранее выделен и оценен в отношении их информативности из большого числа разнообразных признаков [1].

Выделенные фенотипические признаки были изучены у 118 больных РЖ и 55 больных РТК. Мужчин было 78 человек, женщин 95. Возраст больных от 29 лет до 81 года (67\% больных старше 60 лет). Во всех случаях проводили гистологическое исследование операционного материала с определением гистологического типа опухоли, степени ее дифференцировки и стадии развития. Группу сравнения составили 157 человек в возрасте от 63 лет и старше без злокачественных опухолей. Все обследованные относились к славянскому этносу.

Достоверность полученных результатов определяли с использованием t-критерия Стьюдента или критерия Манна-Уитни в зависимости от типа распределения признаков с помощью пакета программ Microsoft Excel. Различия считали достоверными при $\mathrm{p}<0,05$.

\section{РЕЗУЛЬТАТЫ ИССЛЕДОВАНИЯ И ИХ ОБСУЖДЕНИЯ}

Установлено, что для больных РЖ и РТК свойственны следующие фенотипические при- знаки, расцененные нами как «раковые»: группа крови А (II) (имеется у $45 \%$ больных, в группе сравнения - 35\%), светлый цвет радужки глаз (у $77 \%$ опухоленосителей, в группе сравнения $67 \%$ ), волнистый или курчавый тип волос на голове (у $31 \%$ больных РТК и у $51 \%$ больных с РЖ против $15 \%$ в группе сравнения) (табл. 1).

Одновременное сочетание трех «раковых» признаков в группе больных РЖ имелось у 24 человек (20,3\%), в группе больных РТК у 4 человек $(7,3 \%)$, в группе сравнения у 6 человек $(3,8 \%)$. Информативность всего комплекса этих признаков, рассчитанная по формуле Кульбака [2], была значительно выше при РЖ $(0,59$ против 0,25 для РТК). Вместе с тем у опухоленосителей несколько реже встречалась В (III) группа крови $(16,4 \%$ против $20,6 \%$ в группе сравнения), темный цвет глаз (23\% против $33 \%$ в группе сравнения; $\mathrm{p}<0,05)$, прямой тип волос на голове (55\% против $85 \%, \mathrm{p}<0,001)$. Это дало основание рассматривать данные признаки как «антираковые». Комплекс трех «антираковых» признаков у опухоленосителей отсутствовал, однако в группе сравнения он имелся у 9 человек. Дальнейшие расчеты показали, что при наличии у конкретного человека всех трех «раковых» признаков и по достижении им критического возраста (после 60 лет) вероятность возникновения РЖ составляет около $75 \%$, а РТК $60 \%$. Более высокая статистическая значимость «раковых» фенотипических признаков для больных РЖ свидетельствует о том, что в развитии РЖ генетические факторы имеют, по-видимому, большее значение, чем в развитии РТК.

Наличие у больного нескольких «раковых» фенотипических признаков в определенной мере сочетается с тяжестью течения опухолевого процесса. Так, у 64 больных (37\%), имевших 2 или 3 «раковых» признака, опухоли на момент их выявления уже характеризовались наличием лимфогенных и даже гематогенных метастазов, а у 12 из них имелись первично множественные опухоли (сочетания РЖ с раком легких и мочевого пузыря, молочной железы, гортани, кожи).

Таблица 1

Частоты встречаемости наиболее информативных фенотипических признаков у больных злокачественными опухолями и в группе сравнения

\begin{tabular}{|c|c|c|c|}
\hline & $\begin{array}{c}\text { Рак желудка } \\
\text { (118 чел.) }\end{array}$ & $\begin{array}{c}\text { Рак толстого кишечника } \\
\text { (55 чел.) }\end{array}$ & $\begin{array}{c}\text { Группа сравнения } \\
\text { (157 чел.) }\end{array}$ \\
\hline \multicolumn{4}{|c|}{ «Раковые» признаки } \\
\hline Вьющиеся или курчавые волосы & $51 \%$ & $31 \%$ & $15 \%$ \\
\hline Светлые глаза & \multicolumn{2}{|c|}{$77 \%$} & $67 \%$ \\
\hline A (II) & \multicolumn{2}{|c|}{$45 \%$} & $35 \%$ \\
\hline \multicolumn{4}{|c|}{ «Антираковые» признаки } \\
\hline Прямые волосы & $46 \%$ & $69 \%$ & $85 \%$ \\
\hline Темные глаза & \multicolumn{2}{|c|}{$23 \%$} & $33 \%$ \\
\hline B (III) & \multicolumn{2}{|c|}{$16,4 \%$} & $20,6 \%$ \\
\hline
\end{tabular}


Характеристика тяжести течения злокачественных опухолей ЖКТ у больных с разными фенотипическими признаками

\begin{tabular}{|l|c|c|}
\hline & $\begin{array}{c}\text { Больные с «антираковыми» } \\
\text { признаками }\end{array}$ & $\begin{array}{c}\text { Больные с «раковыми» } \\
\text { признаками }\end{array}$ \\
\hline $\begin{array}{l}\text { Наличие метастазов на момент выявления } \\
\text { злокачественной опухоли }\end{array}$ & $11 \%$ & $37 \%$ \\
\hline Первичномножественные опухоли & $2 \%$ & $7 \%$ \\
\hline
\end{tabular}

При наличии двух «антираковых» признаков метастазы на момент выявления злокачественных опухолей имелись лишь у 19 больных (11\%) (разница достоверна, $\mathbf{p}<0,01)$, а первично множественная опухоль была выявлена только у 1 больного (2\%) (табл. 2).

Наглядным примером являются результаты патологоанатомического вскрытия мужчины 49 лет, который имел голубые глаза, А (II) группу крови и вьющиеся волосы. Больной был доставлен в ООКБ по экстренным показаниям в тяжелом состоянии с выраженной одышкой, АД 60/40 мм рт. ст. Умер через 2,5 часа после поступления. Со слов жены, заболел 2 недели назад. На аутопсии обнаружены две злокачественные опухоли: первично-язвенный рак желудка типа низкодифференцированной солидной аденокарциномы и злокачественная карциноидная опухоль обоих легких, растущая диффузно и распространяющаяся перибронхиально. Обе опухоли давали обширные лимфогенные и гематогенные метастазы.

Сочетание светлого цвета радужки глаз, волнистых или курчавых волос и А (II) группы крови может свидетельствовать о повышенной склонности индивида к злокачественным новообразованиям вообще. Это предположение можно подкрепить следующим клиническим примером. У мужчины 75 лет с голубыми глазами, курчавыми волосами и А (II) группой крови в 2005 г. был выявлен рак предстательной железы (умеренно дифференцированная аденокарцинома), больной был радикально прооперирован и в течение 5 лет признаков рецидива опухолевого процесса не было. В 2010 г. возник базальноклеточный рак кожи лица, который своевременно был удален. В декабре 2011 г. появились симптомы нарастающей толстокишечной непроходимости, в дальнейшем развилась желтуха. Диагностирован рак толстого кишечника с метастазами в печень, и в марте 2012 г. больной умер.

Таким образом, наличие комплекса описанных «раковых» фенотипических признаков у лиц славянского этноса может свидетельствовать о принадлежности конкретного их обладателя к группе риска по РЖ и РТК, а в прогностическом отношении при уже развившейся злокачественной опухоли сопряжено с ее более агрессивным течением. Очевидно, суть обнаруженной связи рассмотренных фенотипических признаков с предрасположенностью к РЖ и РТК состоит в том, что гены, кодирующие «раковые» и «антираковые» признаки, сцеплены с генами, определяющими пониженную или, напротив, повышенную резистентность к данным опухолям, и поэтому наследуются в комплексе друг с другом.

Практическая значимость полученных результатов состоит в том, что на их основе можно выделять группы лиц с повышенным риском развития злокачественных опухолей для углубленного и целенаправленного клинического их обследования на предмет выявления начальных стадий развития, а также для организации индивидуальных профилактических мероприятий, способных свести к минимуму риск развития данной патологии в будущем.

\section{ЛИТЕРАТУРА}

1. Барсуков В.С., Гвоздева Е.Г., Стебакова Ю.М., Фотина М.B. Некоторые фенотипические признаки у больных раком желудочно-кишечного тракта и их прогностическое значение // Электронный научнообразовательный вестник «Здоровье и образование в XXI веке». - 2006. - Т. 8, № 2. - С. 67.

2. Гублер Е.В., Генкин А.А. Применение непараметрических критериев статистики в медико-биологических исследованиях. - Л. : Медицина, 1973. - 141 с.

3. Лазебник Л.Б., Хомерики С.Г. Канцеропревенция в гастроэнтерологии // Экспериментальная и клиническая гастроэнтерология. - 2012. - № 5. - С. 3-13.

4. Филимонов А.В., Захарова Н.А., Сиверская Я.В. Скрининг колоректального рака в Ханты-Мансийском автономном округе - Югре // Злокачественные опухоли. -2012 . - Т. 2, № 2 - С. 38-39.

5. Jemal A., Bray F., Center M.M., Ferlay J., Ward E., Forman D. Global cancer statistics // CA Cancer J Clin. - 2011. - Vol. 61, N 2. - P. 69-90. - doi: 10.3322/caac. 20107.

6. Kumar V., Abbas A.K., Aster J.C. Robbins \& Cotran Pathologic Basis of Disease. - 9th Ed. - Elsevier, 2015. 1408 p.

7. La Vecchia C., Bosetti C., Lucchini F., Bertuccio P., Negri E., Boyle P., Levi F. Cancer mortality in Europe, 2000-2004, and an overview of trends since 1975 // Ann Oncol. - 2010. - Vol. 21, N 6. - P. 1323-1360. - doi: 10.1093/annonc/mdp530.

8. Muir's Textbook of Pathology. - 13 Ed. / D. Levison, R. Reid, A.D. Burt, D.J. Harrison, S. Fleming eds. CRC Press, 1992. - P. 700-704; 734-738. 